\title{
FEW CHARACTERISTICS OF DENGUE'S FEVER EPIDEMIOLOGY IN BRAZIL
}

\author{
Maria Glória TEIXEIRA(1)
}

Brazil, in the $21^{\text {st }}$ century, began to occupy the first position in the world ranking of Dengue's Fever (DF) reported cases, with an incidence ranging from 63.2 (2004) to 429.9 (2010) per 100,000 inhabitants (Fig. 1 ), and is among the ten most at risk countries for this disease. When it comes to efforts, from the government and society, aiming to control this disease, the epidemiological situation has been worsening. Currently, in the field of infectious diseases, dengue fever is the main health problem in the country.

In fact, besides the increased incidence that has been noticed, dengue fever expresses in the form of explosive epidemics, affecting urban centers at small and large-scale, causing fear and unsafety to the population, particularly by the risk of Dengue's Hemorrhagic Fever (DHF) occurrence. In these situations, the demand for medical care goes beyond the capacity of network services, the quality of care to affected patients is much less than desired, the distrust of the population in leaders, managers and health services is established, which makes even harder the management of such periods of crisis which succeeds every summer in our country. Thus, a picture of extreme fragility of the Public Health is established.

This scenario is not only due to some conjuncture circumstances because, in addition to the magnitude of DF incidence and the rates of hospitalization in the last 10 years, the increased severity of clinical manifestations of the disease is evidenced. Thus, if in the 1990s the maximum figure for this indicator was 4.0 admissions by dengue fever per 100,000 inhabitants (1998), in the period from 2000 to 2010 this figure has increased reaching 49.7/100,000 inhabitants (2010), a trend that alone reveals the rise of severe dengue fever cases in Brazil (Fig. 2). In turn, the number of cases diagnosed as DHF, according to the strict WHO criteria published in $1997^{7}$, also became more frequent. Therefore, in the period from 1990 to 2000 the proportion of DHF cases in relation to the total reported cases of DF, which was $0.06 \%$, reached $0.46 \%$ in 2010 , corresponding to more than seven times the cases observed in the 1990s.

Another epidemiological feature of dengue fever that, from 2007, has also undergone significant changes, is regarding the distribution by age group. While up to 2006, both DF and DHF affected predominantly adults, in 2007 a shift in the occurrence of DF and DHF was observed to earlier ages ${ }^{2,4,5,6}$.

This worsening is due to the conjunction of several factors, among which stands out the time (more than 25 years) of intense circulation of different serotypes of dengue virus in the country (Fig. 1). This situation has established high levels of specific serotype antibodies in the population, a fact that raises the risk of occurrence of severe cases due to the phenomenon of immune amplification ${ }^{3}$. On the other hand, the magnitude of this risk is not the same for all ages, as it depends on the immunity levels established in each age group for each serotype and specifically the serotype that is more intensive circulating at each time.

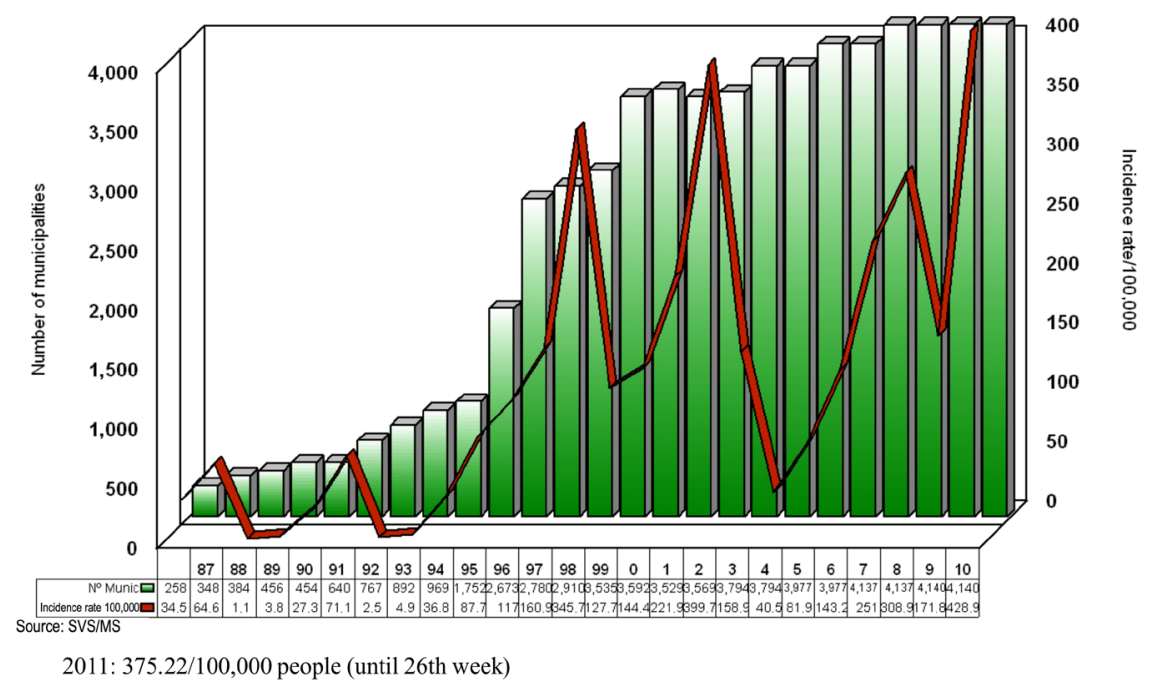

Fig. 1 - Annual distribution of dengue incidence per 100,000 population and number of municipalities infested by Aedes aegypti. Brazil, 1986-2010. 
This dynamics has been determining different patterns of occurrence of severe dengue cases in each urban area, as can be seen in the Brazilian state capitals, provided in Figure 4. Thus, it is verified that currently,
DF and DHF in Brazil has been occurring in all age groups. However, children are paying a higher cost to this disease due to the increased risk of being affected by the severe forms ${ }^{2,4,5,6}$. The introduction of DENV4

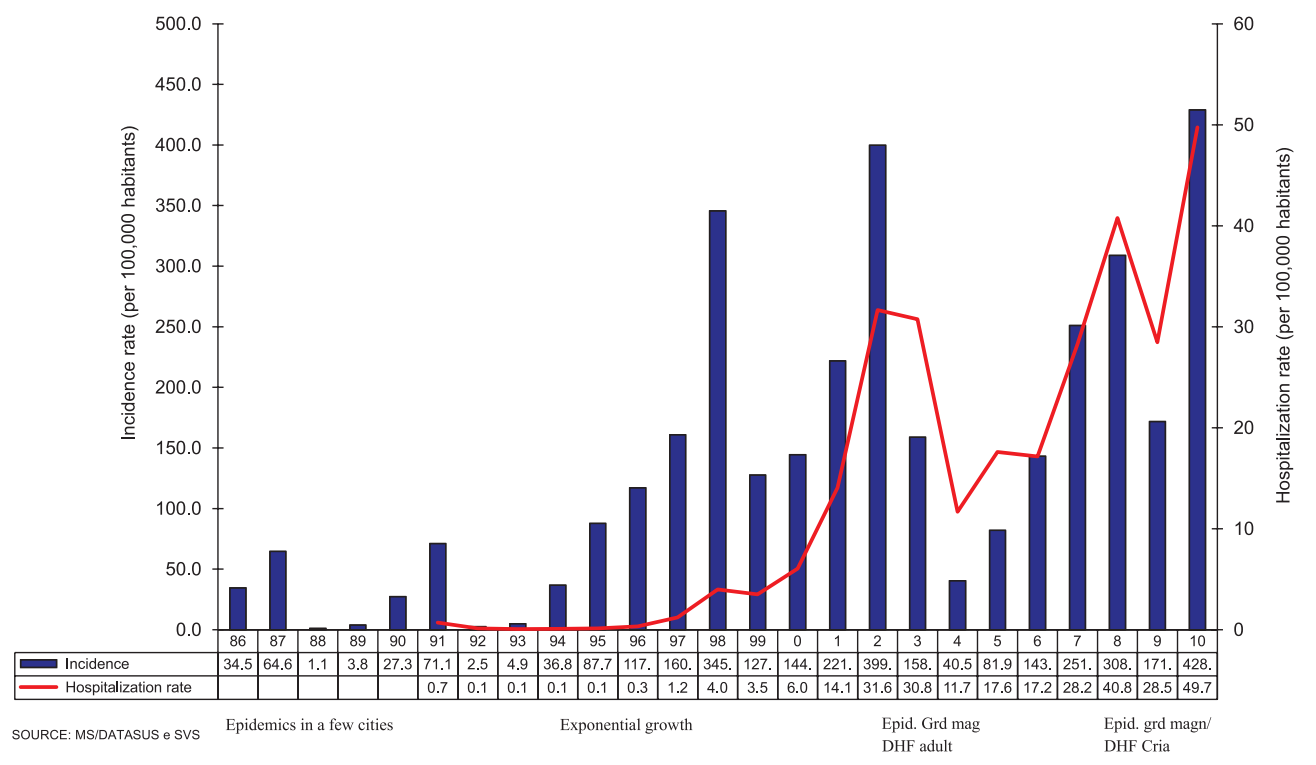

Fig. 2 - Changes in Incidence and Rates of Hospitalization by Dengue. Brazil, 1986 - 2010 .
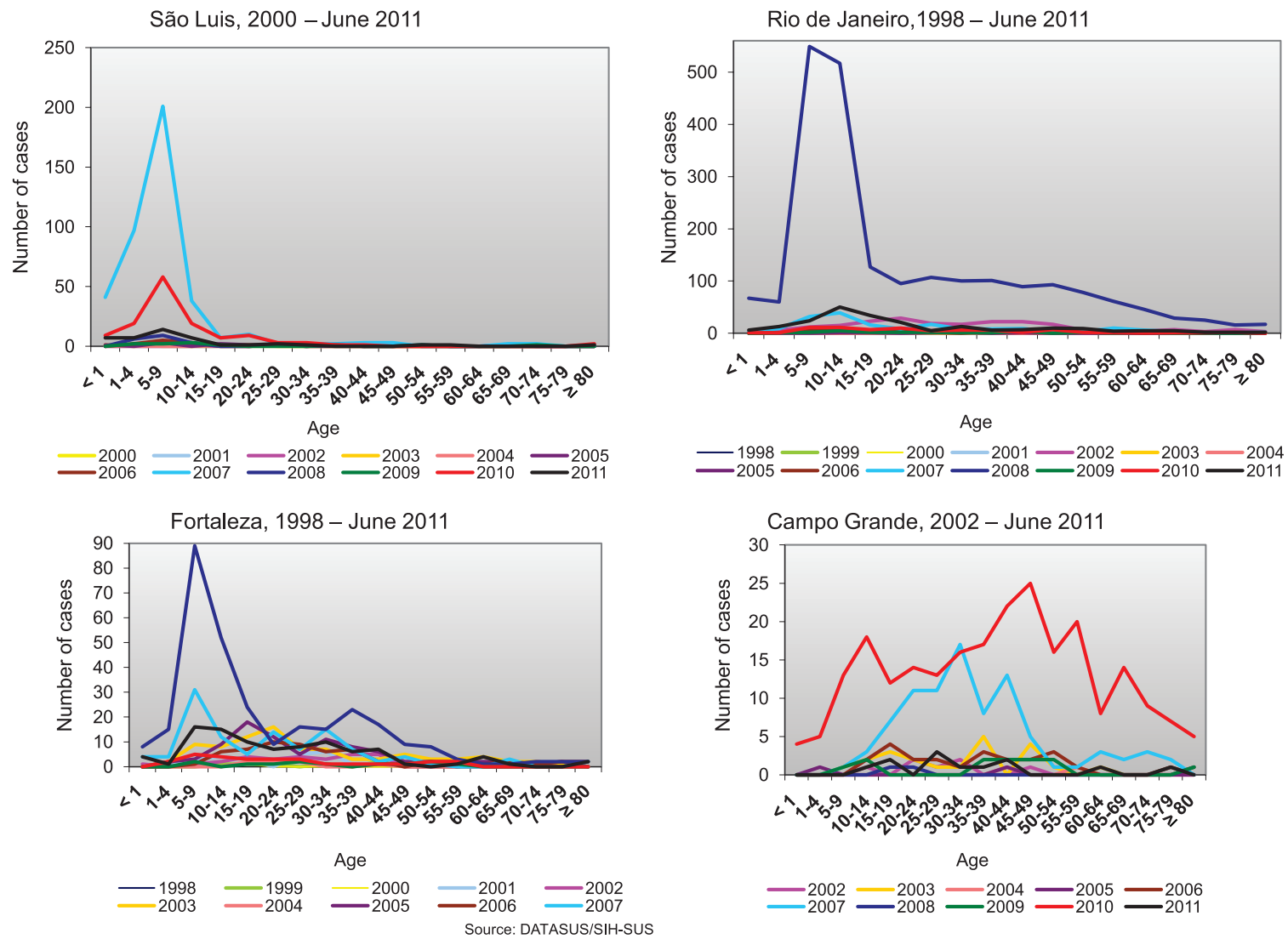

Fig. 3 - Hospitalization for Dengue Hemorrhagic in the SUS network of hospitals, by age group. 
Rio de Janeiro, 1998 - june, 2011

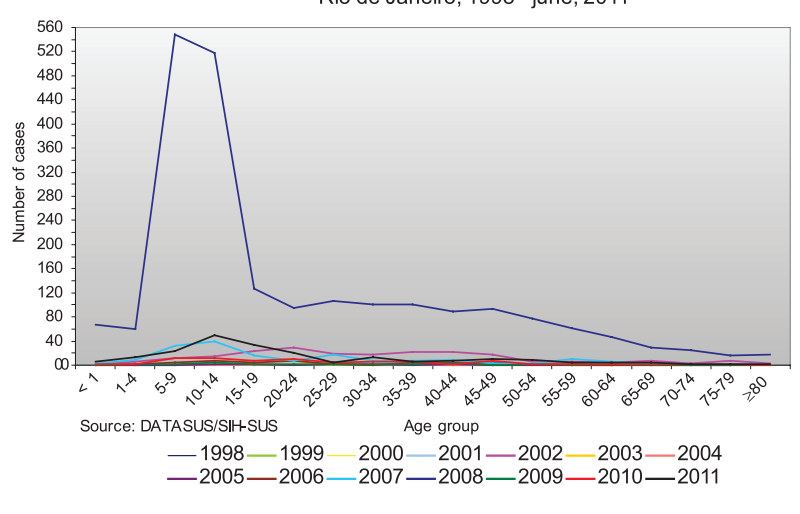

São Luis 2000 - june, 2011

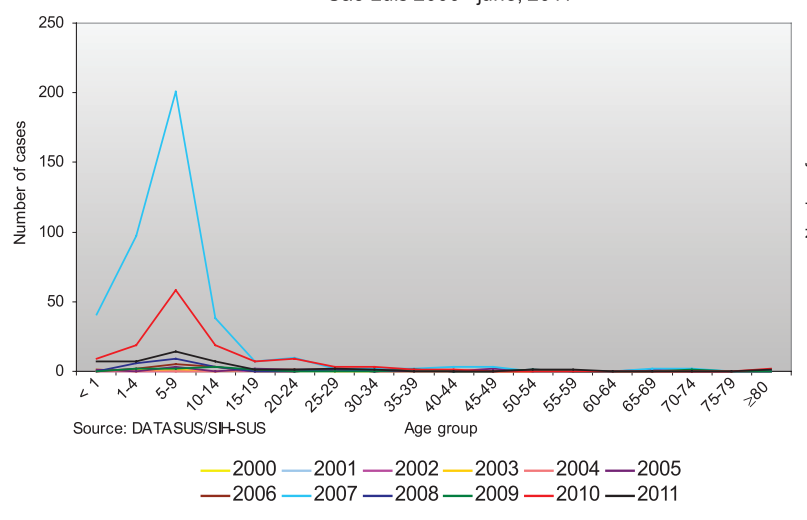

Recife, 1998 - june, 2011

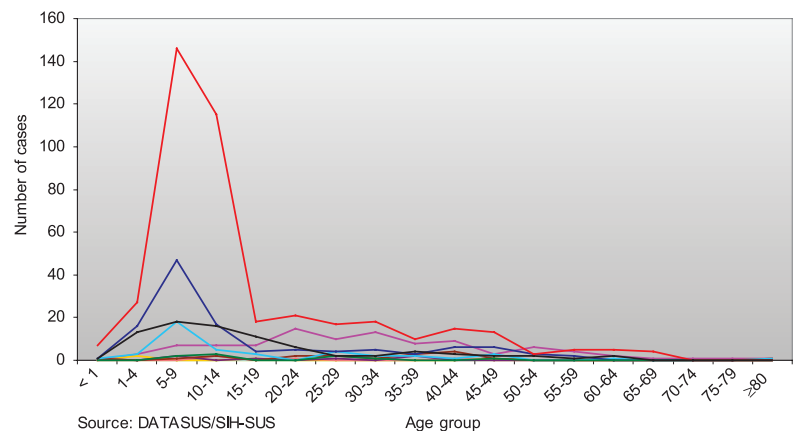
Source: DATASUS/SIH-SUS Age group $-1998-1999-2000-2001-2002-2003-2004$

Cuiabá, 2003 - june, 2011

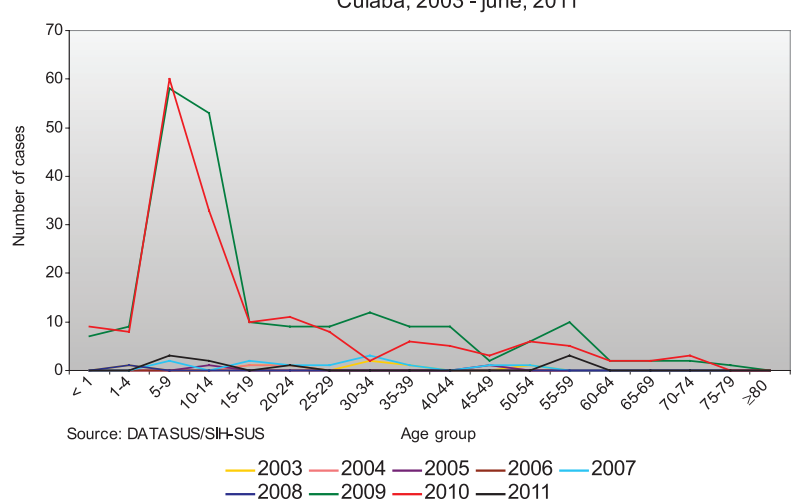

Manaus, $1998-2011$

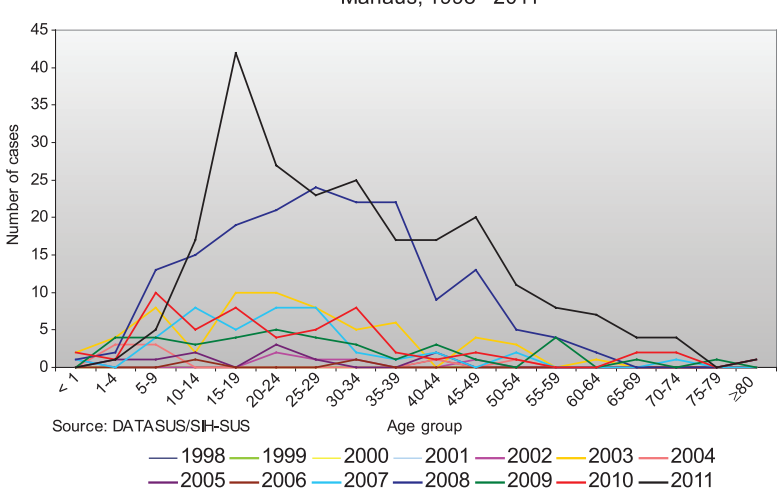

Fortaleza, 1998 - june, 2011

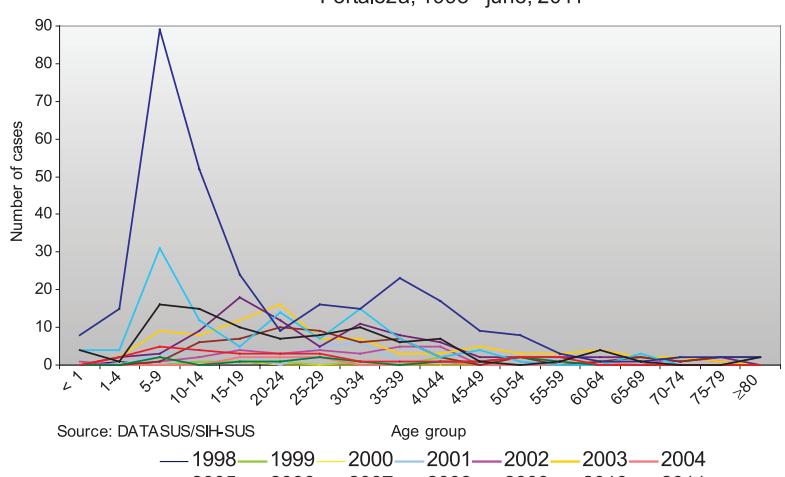

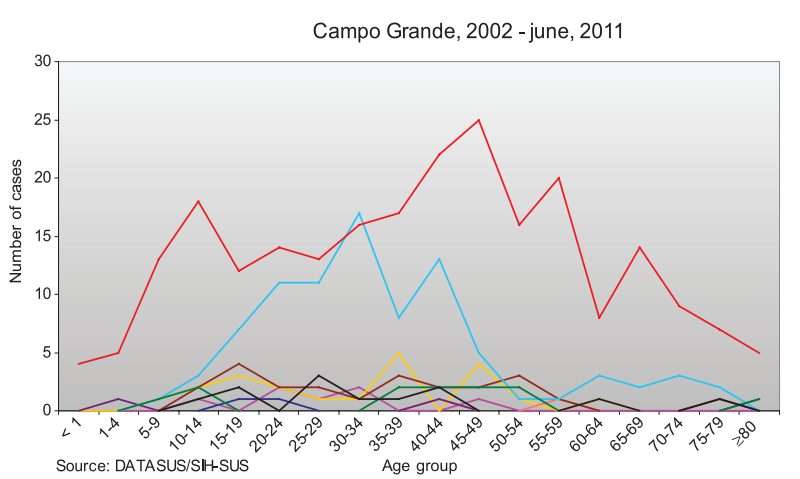
Source: DATASUS/SIH-SUS ${ }^{2}$ ? $\overbrace{}^{2}$ Age group

$$
\begin{gathered}
-2002-2003-2004-2005-2006 \\
-2007-2008-2009-2010-2011 \\
\text { Belém } 1998 \text { - jun, } 2011
\end{gathered}
$$

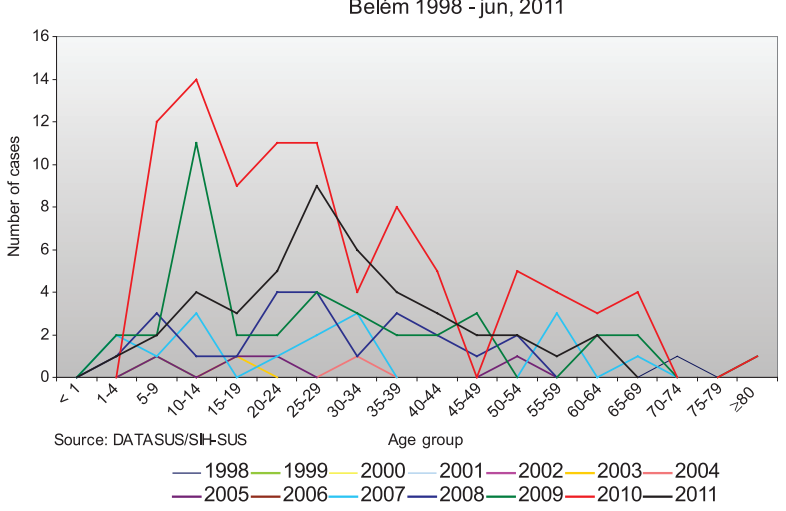

Fig. 4 - Morbidade Hospitalar do SUS - por local de residência - Brasil 
and re-emergence of serotype DENV1 in $2010^{4}$ has pointed to possible new severe epidemics in the next transmission seasons of dengue virus.

Fortunately, it seems that, on the near horizon there is the perspective of new vaccines available to combat dengue virus. However, at least in the upcoming years, there will be no availability for this type of immunogen for the entire population. Moreover, the current vaccine candidate is proposed to be used in three-dose regimen at intervals of six months. These limitations impose initiatives to be taken towards the improvement of medical care to reduce the lethality of the disease as well as improvement and development of new technologies and ways to combat Aedes aegypti. In turn, because of the particularities of epidemiological expression of dengue in time, space and person requires that vaccination strategies to be adopted in Brazil consider immunity per age group, history and dengue trend at each site, individual risk factors, in addition to joint actions for vector combat in all aspects (social participation, chemical control, sanitation, etc). Therefore, the use of a vaccine against dengue fever will require the efforts of the "epidemiological intelligence" in the country in view of the search for impact on the occurrence of dengue from these interventions.

\section{REFERENCES}

1. Brasil, Ministério da Saúde, Secretaria de Vigilância em Saúde. Dados fornecidos pela gerência técnica do Programa Nacional de Controle de Dengue. Brasília: Ministério da Saúde; 2008.

2. Cavalcanti LP, Vilar D, Souza Santos R, Teixeira MG. Change in age pattern of persons with dengue, northeastern Brazil. Emerg Infect Dis. 2011;17:132-4.

3. Halstead SB. The pathogenesis of dengue. Molecular epidemiology in infections disease. Am J Epidemiol. 1981;114:632-48.

4. Siqueira Júnior JB, Vinhal LC, Said RFC, Hoffmann JL, Martins J, Barbiratto SB, et al. Dengue no Brasil: tendências e mudanças na epidemiologia, com ênfase nas epidemias de 2008. In: Saúde Brasil 2010: uma análise da situação de saúde e de evidências selecionadas de impacto de ações de vigilância em saúde. Brasília; Ministério da Saúde; 2011. p. 157-71.

5. Teixeira MG, Costa MC, Coelho GE, Barreto ML. Recent shift in age pattern of dengue hemorrhagic fever, Brazil. Emerg Infect Dis. 2008;14:1663.

6. Teixeira MG, Costa MC, Barreto FR,Barreto ML. Dengue: twenty-five years since reemergence in Brazil. Cad Saude Publica. 2009;25(Suppl 1):S7-18.

7. World Health Organization. Dengue haemorrhagic fever: diagnosis, treatment, prevention and control. Geneva: WHO; 1997. 